\title{
PREVENTIVE EFFECT OF CYCAS REVOLUTA IN 1,2-DIMETHYLHYDRAZINE-INDUCED COLON CANCER IN WISTAR RAT MODEL
}

\author{
SAMIT BERA, BHASKAR DAS, ARNAB DE, AMALESH SAMANTA*
}

Department of Pharmaceutical Technology, Jadavpur University, Kolkata, West Bengal, India. Email: asamanta61@yahoo.co.in

Received: 05 December 2017, Revised and Accepted: 20 January 2018

ABSTRACT

Objective: The aim of this study was to evaluate the colon cancer protective activity of Cycas revoluta (Cycadaceae).

Methods: Methanolic extracts of $C$. revoluta (MECR) were assessed for total polyphenols and total flavonoids content. For the in vivo study, animals were divided into five groups $(\mathrm{n}=6)$. Group I serves as control which received $0.25 \%$ carboxymethyl cellulose solution. Groups II-V were treated with 1,2-dimethylhydrazine (DMH) which was given at the dose of $20 \mathrm{mg} / \mathrm{kg}$ b.w., s.c. once a week for 4 consecutive weeks. Aqueous suspension of MECR at a dose of $200 \mathrm{mg} / \mathrm{kg} /$ day and $400 \mathrm{mg} / \mathrm{kg}$ was administered orally to the animals in Groups III-IV every day for 16 weeks. Group V received 5 -fluorouracil (5-FU) as a standard drug at a dose of $10 \mathrm{mg} / \mathrm{kg}$ b.w., per day s.c. for 16 weeks. After that, animals are sacrificed and colons are taken separately to evaluate biochemical parameters and morphological and histopathological changes.

Results: MECR contains total polyphenols $(6.3 \pm 0.09 \mathrm{mg}$ of gallic acid equivalent $/ \mathrm{g}$ ) and total flavonoids (4.6 $\pm 0.06 \mathrm{mg}$ of rutin equivalent/g). The in vivo study revealed that superoxide dismutase (SOD), catalase, and reduced glutathione (GSH) activity were decreased in DMH Group. All these parameters were restored significantly $(\mathrm{p}<0.05)$ toward the near normal value on supplementation with MECR (200 and 400 mg/kg b.w.) to DMHtreated rats (Groups III and IV). In Group V, the synthetic standard drug 5-FU (10 mg/kg b.w.) also increases the activities of SOD, CAT, and GSH significantly $(\mathrm{p}<0.05)$ more in DMH-treated rats.

Conclusions: It can be concluded that MECR protects rat from DMH-induced colon cancer.

Keywords: Cycas revoluta, Methanolic extracts of C. revoluta, 1, 2-Dimethylhydrazine, Colon cancer, 5-Fluorouracil.

(C) 2018 The Authors. Published by Innovare Academic Sciences Pvt Ltd. This is an open access article under the CC BY license (http://creativecommons. org/licenses/by/4. 0/) DOI: http://dx.doi.org/10.22159/ajpcr.2018.v11i5.24126

\section{INTRODUCTION}

Colon cancer is the most fatal issues throughout the world and a leading cause of cancer-related mortality. Oxidative stress is one of the main causes of colon cancer [1]. The gastrointestinal tract is more susceptible to toxic chemical exposure which may execute the chronic inflammation, and later, it becomes tumour in the gastrointestinal tract [2]. Over the past few years, the first-line clinical treatments for colon cancer patients are cytoreductive surgery and combined chemotherapy [3]. Drug resistance results in a poor overall survival rate [4]. Therefore, the development of effective and less toxic drugs is urgent for colon cancer patients.

The colon-specific carcinogen 1,2-dimethylhydrazine (DMH) induces the formation of methyl adducts with DNA bases and causes point mutations [5]. This adduct interferes with normal cell growth by altered normal gene transcription. After the Phases I and II metabolism, carcinogenic metabolites are produced from DMH. The activation of carcinogen is done by Phase I enzymes. The pro-carcinogen DMH undergoes hydroxylation in Phase I reactions catalyzed by cellular microsomal monooxygenases to produce strong electrophiles. The produced strong electrophiles are capable of interacting with cellular nucleophiles such as DNA to form adducts causing mutagenesis and neoplastic transformation. By Phase II biotransformation, these electrophilic intermediates are detoxified by enzymes such as glutathione (GSH) S-transferase [6]. Due to binding of DMH metabolite to DNA, gene transcription is modified to create oxidative stress through the production of reactive oxygen species (ROS) inside the cells. The ROS has pathological status by inducing oxidative stress-mediated inflammatory response in several tissues [7]. Increase in ROS level is an important factor to develop colitis-associated colon cancer [8]. There are several endogenous antioxidant such as superoxide dismutase (SOD),
CAT, and GSH increase in normal colon cell in response to small increase of ROS, but in DMH-induced rats due to modification gene transcription, excessive ROS is produced crossing the level of endogenous antioxidant production. As a result, DNA damage occurs leading to colon cancer and less production of endogenous antioxidant. After the DNA damage, ROS is produced in fewer amounts for the survival of colon cancer cells.

Cycas revoluta, one of the most primitive living seed plants, contains edible starch in pith, and is used for making sago. Seeds of this plant contain cycasin which is a neurotoxin when consumed orally due to aglycone release from glycoside after acid hydrolysis in the stomach [9]. Although seeds contains toxin, the $C$. revoluta cone is used in the painful urination by the hilly people of Northeast India [10]. It is reported for the seeds to possess profound anticancer activity against colon cancer [11]. The plant contains several important chemicals including dihydroamentoflavone glucosides [12], peptides [11], chitinase [13], mannose-specific lectins [14], and beta-D-glucosidase [15]. C. revoluta has been reported to have many pharmacological effects such as antioxidant [16], anti-inflammatory, anticancer, antileishmaniasis [12], and antimicrobial [11]. A recent study [11] has reported the anticancer activity of $C$. revoluta seeds on human colon carcinoma cells (HCT-15). However, till now, no reports are available on the colon cancer protective effect of $C$. revoluta cone (male flower) on the DMH-induced colon cancer. Therefore, the present work was intended to evaluate the efficacy of methanolic extract of $C$. revoluta (MECR) cone against DMHinduced colon cancer in Wistar rat model.

\section{MATERIALS AND METHODS}

Materials

$\mathrm{DMH}$, methanol, 5-fluorouracil (5-FU), phenazine methosulphate, NBT, reduced nicotinamide adenine dinucleotide, glacial acetic acid, 
n-butanol, pure SOD, $\mathrm{H}_{2} \mathrm{O}_{2}$, pure catalase (CAT), phosphate buffer, ethylenediaminetetraacetic acid, trichloroacetic acid, Tris-HCL, Dithiobis (2-nitrobenzoic acid), pure reduced GSH, anddd sodium dodecyl sulfate were purchased from Sigma Laboratories, Germany.

\section{Animals}

The experimental protocols involving animals were approved by the Institutional Animal Ethics Committee (NCPT/IAEC-15/2015), and the experiments on animals were performed in accordance with the Committee for the Purpose of Control and Supervision of Experimentation on Animals guidelines. Experiments were performed on male Wistar rats (5 weeks old) procured from Indian Institute of Chemical Biology, Kolkata, India. The animals were fed standard balanced diet and drinking water and were maintained with $24 \mathrm{~h}$ day and night cycle. The animals were acclimatized for 2 weeks before starting of the experimentation.

\section{Plant material}

Fresh male cone was collected from the village of Srirampur under East Midnapur district and authenticated (Voucher Ref. No.: BSI/Pharma/ SD/Tech./2016) by botanist, Dr. A B D Selvam of Botanical Survey of India (BSI), Shibpur, Howrah (West Bengal). The cones were cut into small pieces and dried in the shade below $50^{\circ} \mathrm{C}$. Then, dried cone pieces were powdered in mixture grinder and stored in airtight container.

\section{Extraction of plant extract}

The cones were cut into small pieces and were shade dried and then milled into a coarse powder. Then, the air dried and powdered cones $(175 \mathrm{~g})$ were first defatted with petroleum ether $\left(60-80^{\circ} \mathrm{C}\right)$ and then extracted with $2.5 \mathrm{~L}$ of methanol (90\%) using Soxhlet apparatus. The solvent was then removed with repeated lyophilization. After drying, $11.7 \mathrm{~g}(6.6 \%$ yield $)$ extract was obtained.

\section{Determination of total polyphenolic compounds}

UV spectrophotometric method was used to determine the concentration of phenolics in the plant extracts [17]. The content of total phenolics in extracts was expressed as mg gallic acid equivalent (GAE) per g of dry weight of extract (mg GAE/g DW).

\section{Determination of total flavonoid content}

The content of flavonoids in plant extracts was determined using spectrophotometric method [17]. The content of flavonoids in extracts was expressed as $\mathrm{mg}$ of rutin equivalent (RUE) per $\mathrm{g}$ of dry weight of extract (mg RUE/g DW).

\section{Acute toxicity study}

MECR in olive oil was administered orally to the animals in increasing doses up to $2000 \mathrm{mg} / \mathrm{kg}$ b.w. These animals were observed for $2 \mathrm{~h}$ for behavioral, neurological, and autonomic profiles and mortality and toxicity for $72 \mathrm{~h}$.

\section{In vivo experimental design for induction of colon cancer}

Animals were divided into five groups $(\mathrm{n}=6)$. Group I serves as a vehicle control which received $0.25 \%$ carboxymethyl cellulose solution. Groups II-V were treated with DMH was given at the dose of $20 \mathrm{mg} / \mathrm{kg}$ b.w., s.c. once a week for 4 consecutive weeks. Aqueous suspension of MECR at a dose of $200 \mathrm{mg} / \mathrm{kg} /$ day and $400 \mathrm{mg} / \mathrm{kg}$ was administered orally to the animals in Groups III to IV every day for 16 weeks. Group V received 5-FU as a standard drug at a dose of $10 \mathrm{mg} / \mathrm{kg}$ b.w., per day s.c. for 16 weeks [18].

\section{Macroscopic evaluation of the incidence of polyps}

At the end of the experiment, rats were sacrificed and colons were taken out and flushed with phosphate-buffered saline. The colons were cut to open longitudinally without disturbing the polyps and carefully counted through visual macroscopic examination. Then, the colons were verified histopathologically.
In vivo antioxidant status determination

After 16 weeks of treatment, rats were kept one night fasting and then sacrificed to collect colons . After washing in ice-cold saline, colons were kept in deep freeze $\left(-20^{\circ} \mathrm{C}\right)$ to conduct the different types of biochemical tests. Then, the colon was taken out separately for each time just before the specific biochemical test to be conducted. Colon tissues were homogenated using homogenizer. For homogenization, $0.5 \mathrm{~g}$ of colon was taken in $5 \mathrm{ml}(\mathrm{w} / \mathrm{v})$ ice-cold saline followed by centrifugation at $2000 \mathrm{~g}$ for $10 \mathrm{~min}$. The supernatant was used for evaluating the level of enzymatic antioxidant such as SOD and catalase (CAT) activity and non-enzymatic antioxidant such as reduced GSH [19].

\section{Histological observation}

Histological evaluation was performed in colon tissues. A portion of the specimen was fixed in $10 \%$ formalin and embedded in paraffin wax, sectioned at $4 \mu \mathrm{m}$ thickness, and was stained with hematoxylin and eosin. Morphological changes of colon were evaluated by light microscopy method in control and experimental groups of animals [20].

\section{Statistical analysis}

All the data were evaluated with Graph Pad Prism version 5 software (GraphPad Software Inc, La Jolla, CA). Hypothesis testing methods included one-way analysis of variance (ANOVA) followed by Dunnett's t-test to correct for multiple comparisons with acceptable statistical level significance $(p<0.05)$. Each experiment was presented as the mean \pm SEM.

\section{RESULTS}

Total polyphenolic and total flavonoid content

MECR contains total polyphenols $(6.3 \pm 0.09 \mathrm{mg}$ of GAE/g) and total flavonoids ( $4.6 \pm 0.06 \mathrm{mg}$ of RUE/g) (Table 1 ).

\section{Acute toxicity study}

In the acute toxicity assay, it was found that no mortality was observed up to doses $2000 \mathrm{mg} / \mathrm{kg}$ b.w. orally and was considered as safe, and no lethality or any toxic reaction was found up to the end of the study period. By keeping $1 / 5^{\text {th }}(400 \mathrm{mg} / \mathrm{kg}$ ) dose as highest, $200 \mathrm{mg} / \mathrm{kg}$ was selected as working doses for the present study.

\section{Effect of DMH and MECR on polyps incidence}

In the DMH-alone-treated rats (Group II), 100\% incidence of polyps was found (Table 2). On supplementation with different doses of MECR (200 and $400 \mathrm{mg} / \mathrm{kg}$ b.w.) to DMH-induced rats (Groups III-IV), the incidence of polyps was significantly reduced as compared to DMHalone induced rats (Group II). No specific changes were noticed control rats (Groups I). $400 \mathrm{mg} / \mathrm{kg}$ b.w., MECR was found to be effective, the incidence of polyps being $33.33 \%$, but it was slightly less effective than the synthetic standard drug $5-\mathrm{FU}(10 \mathrm{mg} / \mathrm{kg}$ b.w.), the incidence of polyp being $13.33 \%$.

\section{Effect of MECR on different antioxidant enzyme activity}

SOD, catalase, and reduced GSH activity were decreased in DMH Group. All these parameters were restored significantly $(p<0.05)$ toward the near normal value on supplementation with MECR $(200$ and $400 \mathrm{mg} / \mathrm{kg}$ b.w.) to DMH-treated rats (Groups III and IV). In Group V, the synthetic drug 5-FU (10 mg/kg b.w.) also increases the activities of SOD, CAT, and GSH significantly $(\mathrm{p}<0.05)$ more in DMH-treated rats (Fig. 1).

Table 1: Phytochemical content of MECR

\begin{tabular}{ll}
\hline Phytochemical constituents & Value \\
\hline Total phenolic content (mg of GAE/g of DW extract) & $6.3 \pm 0.09$ \\
Total flavonoid content (mg of rutin/g of DW extract) & $4.6 \pm 0.06$ \\
\hline
\end{tabular}

Values were expressed as mean \pm SEM ( $n=3)$. MECR: Methanolic extract of Cycas revoluta, C. revoluta: Cycas revoluta 
Table 2: Effect of MECR on the incidence of colonic polyps in the different groups

\begin{tabular}{|c|c|c|c|c|c|c|}
\hline Groups & $\begin{array}{l}\text { Number } \\
\text { of rats }\end{array}$ & $\begin{array}{l}\text { Number of polyps } \\
\text { bearing rats }\end{array}$ & $\begin{array}{l}\text { Total number } \\
\text { of polyps }\end{array}$ & $\begin{array}{l}\text { Average number } \\
\text { of polyps bearing } \\
\text { rats }^{\mathrm{a}}\end{array}$ & $\begin{array}{l}\text { Percentage } \\
\text { incidence of polyps }^{b}\end{array}$ & $\begin{array}{l}\text { Percentage of } \\
\text { polyps inhibition }\end{array}$ \\
\hline Control (I) & 6 & 0 & Nil & Nil & - & - \\
\hline DMH (II) & 6 & 6 & 15 & 2.5 & 100 & 0 \\
\hline DMH+MECR200 (III) & 6 & 5 & 9 & 1.8 & 60 & 40 \\
\hline DMH+MECR400 (IV) & 6 & 3 & 5 & 1.67 & 33.33 & 66.67 \\
\hline $\mathrm{DMH}+5-\mathrm{FU}(\mathrm{V})$ & 6 & 2 & 2 & 1 & 13.33 & 86.67 \\
\hline
\end{tabular}

DMH: 1,2-dimethylhydrazine (20 mg/kg b.w.), MECR200: Methanolic extract of Cycas revoluta (200 mg/kg b.w.), MECR400: Methanolic extract of Cycas revoluta ( $400 \mathrm{mg} / \mathrm{kg}$ b.w.), 5-FU: 5-Fluoro-uracil $\left(10 \mathrm{mg} / \mathrm{kg}\right.$ b.w.). ${ }^{\mathrm{a}}$ Total number of polyps/number of polyps-bearing rats in each group. ${ }^{\mathrm{b}}$ (Total number polyps/total number of polyps in DMH group) $\times 100$

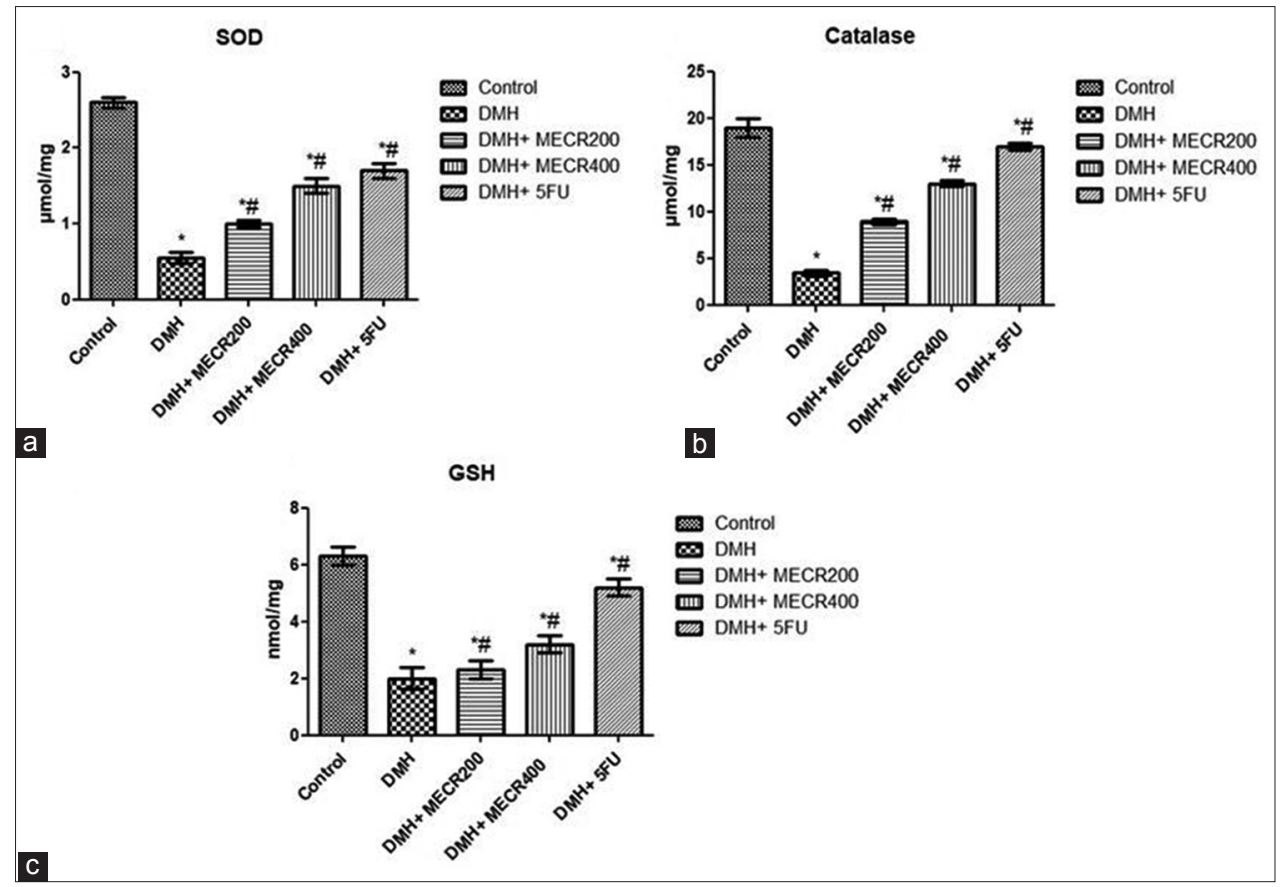

Fig. 1: Evaluation of biochemical parameters in colon homogenate in control (I), DMH (II), DMH+MECR200 (III), DMH+MECR400 (IV), $\mathrm{DMH}+5 \mathrm{FU}$ (V) groups. (a) Superoxide dismutase, (b) catalase, (c) reduced GSH. Values were expressed as mean \pm SEM $(\mathrm{n}=6)$. All groups are compared to control group. *Significantly $(\mathrm{p}<0.05)$ different from control group when compared with other groups by Dunnett's t-test in one-way ANOVA analysis. \#Treatment groups are compared with DMH Group $(p<0.05)$ by Dunnett's t-test in one-way ANOVA analysis

\section{Histopathological evaluation}

The colon of control group showed normal mucosa and submucosal layers and normal colonic architecture without apparent abnormality in (Fig. 2a). DMH-induced group showed clear degeneration as the size of the cells smaller than that of normal (Fig. 2b). In DMH+MECR200 group, mucosal and submucosal layers were less ruptured compared to DMHinduced group (Fig. 2c). In DMH+MECR400 group, the mucosal epithelial architecture along with sub-mucosal layer's integrity was better than that of DMH+MECR200 group (Fig. 2d). Tubular glands gradually appeared clearly as the doses of MECR increased. However, DMH+5FUtreated group showed better results as compared to DMH+MECR400 group as tubular gland appeared clearly with arranged manner (Fig. 2e).

DMH group shows that tubular glands in mucosal and submucosal layer are not observed prominently. Tubular glands size is smaller in DMH Group than that of control group. Degenerative changes was observed at mucosal and submucosal layer in DMH Group. Tubular glands gradually appeared clearly as the doses of MECR increased. In DMH+5FU group, degenerative changes are least than those of DMH+MECR 200 group and DMH+MECR 400 group (magnification, $\times 40$ ).

\section{DISCUSSION}

Colon cancer was induced with DMH in Wistar rats through its metabolite azoxymethane which is potent genotoxic agents to trigger oxidative stress through DNA methylation of colonic epithelial cells [21]. This adduct interferes with normal cell growth by altered normal gene transcription. Due to binding of DMH metabolite to DNA, gene transcription is modified to create oxidative stress through the production of ROS inside the cells. Increase in ROS level is an important factor to develop colitis-associated colon cancer [8]. There are several endogenous antioxidants such as SOD, CAT, and GSH increase in normal colon cell in response to small increase of ROS, but in DMH-induced rats due to modification gene transcription, excessive ROS is produced crossing the level of endogenous antioxidant production. As a result, DNA damage occurs leading to colon cancer and less production of endogenous antioxidant. After the DNA damage, ROS is produced in fewer amounts for the survival of colon cancer cells. In the in vivo model, the levels of endogenous antioxidants SOD, CAT, and GSH were restored after administration of MECR in DMH-induced rats but not restored in only DMH-consumed rats. Endogenous antioxidant restoration by MECR occurs due to replacement of cancer cell in colon causing death in consequence of ROS increase by polyphenolic and flavonoid in MECR [22]. On the other hand, endogenous antioxidant increases in normal cell in response to ROS to reduce its level [23]. Polyphenolics and flavonoids of MECR are antioxidant [24] which perform anticancer [25] activity ultimately in rat colon. Hence, colon cancer polyps are less observed in MECR-treated group and polyp number decreases dosedependent manner. 


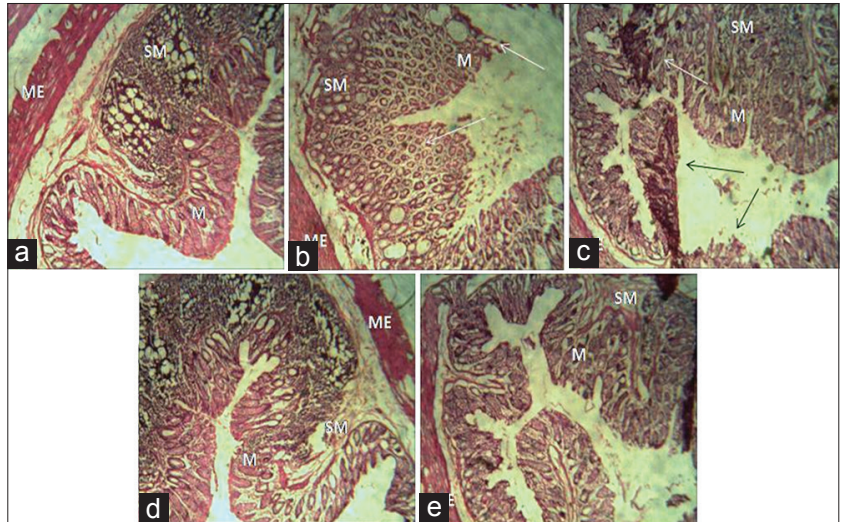

Fig. 2: Histopathological evaluation of colon. M - mucosal layer, SM - submucosal layer, ME - muscularis externa. Arrows indicate the degenerative changes due to DMH. (a) Normal control Group (I), (b) DMH Group (toxic control) (II), (c) DMH+MECR200 Group (III), (d) DMH+MECR400 Group (IV), (e) DMH+5-FU Group (V)

Furthermore, our histological observation revealed that clusters of abnormal degenerated glands and cells in the mucosal lining of the colon and rectum were observed in animals of DMH group along with severe mucosal and submucosal damage. However, animals treated with orally administered MECR show replacement of abnormal cell in the DMH-treated animals, justifying the anticancer potential of MECR.

\section{CONCLUSION}

From this study, it can be concluded that MECR might be a colon cancer protective agent. The present study opens many new areas of research work. This work can be continued in the future to study and to make it clinically applicable for colon cancer protective activity in different experimental models and also to isolate, identify, characterize, and standardize the active principle(s) that are responsible for this activity.

\section{CONFLICT OF INTEREST}

The authors declare no conflict of interest.

\section{REFERENCES}

1. Martín MA, Goya L, Ramos S. Preventive effects of cocoa and cocoa antioxidants in colon cancer. Diseases 2016;4.

2. Castellsagué X, Muñoz N, De Stefani E, Victora CG, Castelletto R, Rolón PA, et al. Influence of mate drinking, hot beverages and diet on esophageal cancer risk in South America. Int J Cancer 2000;88:658-64.

3. Glehen O, Kwiatkowski F, Sugarbaker PH, Elias D, Levine EA, De Simone M, et al. Cytoreductive surgery combined with perioperative intraperitoneal chemotherapy for the management of peritoneal carcinomatosis from colorectal cancer: A multi-institutional study. J Clin Oncol 2004;22:3284-92.

4. Mirakhorli M, Rahman SA, Abdullah S, Vakili M, Rozafzon R, Khoshzaban A, et al. Multidrug resistance protein 2 genetic polymorphism and colorectal cancer recurrence in patients receiving adjuvant FOLFOX-4 chemotherapy. Mol Med Rep 2013;7:613-7.

5. Samanta S, Swamy V, Suresh D, Rajkumar M, Rana B, Rana A, et al. Protective effects of vanadium against $\mathrm{DMH}$-induced genotoxicity and carcinogenesis in rat colon: Removal of $\mathrm{O}(6)$-methylguanine DNA adducts, p53 expression, inducible nitric oxide synthase downregulation and apoptotic induction. Mutat Res 2008;650:123-31.

6. Sheweita SA, Tilmisany AK. Cancer and phase II drug-metabolizing enzymes. Curr Drug Metab 2003;4:45-58.

7. Kolls JK. Oxidative stress in sepsis: A redox redux. J Clin Invest 2006; $116: 860-3$

8. Liochev SI. Reactive oxygen species and the free radical theory of aging. Free Radic Biol Med 2013;60:1-4.

9. Hirayama B, Hazama A, Loo DF, Wright EM, Kisby GE. Transport of cycasin by the intestinal $\mathrm{Na}+$ /glucose cotransporter. Biochim Biophys Acta 1994;1193:151-4.

10. Rout J, Sajem AL, Nath M. Medicinal plants of North Cachar Hills district of Assam used by the Dimasa tribe. Indian J Tradit Knowl 2012;11:520-27.

11. Mandal SM, Migliolo L, Das S, Mandal M, Franco OL, Hazra TK, et $a l$. Identification and characterization of a bactericidal and proapoptotic peptide from Cycas revoluta seeds with DNA binding properties. J Cell Biochem 2012;113:184-93.

12. Moawad A, Hetta M, Zjawiony JK, Ferreira D, Hifnawy M. Two new dihydroamentoflavone glycosides from Cycas revoluta. Nat Prod Res 2014;28:41-7.

13. Taira T, Fujiwara M, Dennhart N, Hayashi H, Onaga S, Ohnuma T, et al. Transglycosylation reaction catalyzed by a class $\mathrm{V}$ chitinase from cycad, Cycas revoluta: A study involving site-directed mutagenesis, HPLC, and real-time ESI-MS. Biochim Biophys Acta 2010;1804:668-75.

14. Nakamura S, Yagi F, Totani K, Ito Y, Hirabayashi J. Comparative analysis of carbohydrate-binding properties of two tandem repeat-type jacalin-related lectins, Castanea crenata agglutinin and Cycas revoluta leaf lectin. FEBS J 2005;272:2784-99.

15. Yagi F, Hatanaka M, Tadera K, Kobayashi A. Beta-D-glucosidase from seeds of Japanese cycad, Cycas revoluta thunb.: Properties and substrate specificity. J Biochem 1985;97:119-26.

16. Lolodi O, Eriyamremu GE. Effect of methanolic extract of Vernonia amygdalina (common bitter leaf) on lipid peroxidation and antioxidant enzymes in rats exposed to cycasin. Pak J Biol Sci 2013;16:642-6.

17. Stanković MS. Total phenolic content, flavanoid concentration and antioxidant activity of Marrubium peregrinum L. Extracts. Kragujev J Sci 2011;33:63-72

18. Sivaranjani A, Sivagami G, Nalini N. Chemopreventive effect of carvacrol on 1,2-dimethylhydrazine induced experimental colon carcinogenesis. J Cancer Res Ther 2016;12:755-62.

19. Arigesavan K, Sudhandiran G. Carvacrol exhibits anti-oxidant and anti-inflammatory effects against 1,2-dimethyl hydrazine plus dextran sodium sulfate induced inflammation associated carcinogenicity in the colon of fischer 344 rats. Biochem Biophys Res Commun 2015;461:314-20.

20. da Rocha BA, Ritter AM, Ames FQ, Gonçalves OH, Leimann FV, Bracht L, et al. Acetaminophen-induced hepatotoxicity: Preventive effect of trans anethole. Biomed Pharmacother 2017;86:213-20.

21. Hong MY, Chapkin RS, Wild CP, Morris JS, Wang N, Carroll RJ, et al. Relationship between DNA adduct levels, repair enzyme, and apoptosis as a function of DNA methylation by azoxymethane. Cell Growth Differ 1999;10:749-58

22. Matsuo M, Sasaki N, Saga K, Kaneko T. Cytotoxicity of flavonoids toward cultured normal human cells. Biol Pharm Bull 2005;28:253-9.

23. Wattel A, Kamel S, Mentaverri R, Lorget F, Prouillet C, Petit JP, et al. Potent inhibitory effect of naturally occurring flavonoids quercetin and kaempferol on in vitro osteoclastic bone resorption. Biochem Pharmacol 2003;65:35-42.

24. Reza MM, Sohelia M, Farkhondeh M. Study the relationship between antioxidant potential and phenolic contents of Juniperus excelsa fruit. Int J Pharm Pharm Sci 2014;6:192-94.

25. Sharma R, Chandan G, Chahal A, Saini RV. Antioxidant and anticancer activity of methanolic extract from Stephania elegans. Int J Pharm Pharm Sci 2016;9:245-49. 